\title{
Dietary patterns are associated with child, maternal and household-level characteristics and overweight/obesity among young Samoan children
}

\author{
Courtney C Choy ${ }^{1,} \uparrow$, Dongqing Wang ${ }^{2} \uparrow$, Ana Baylin ${ }^{2,3}$, Christina Soti-Ulberg ${ }^{4}$, Take \\ Naseri $^{4}$, Muagututia S Reupena ${ }^{5}$, Avery A Thompson ${ }^{6}$, Rachel L Duckham ${ }^{7,8}$ and \\ Nicola L Hawley ${ }^{6, *}$ \\ 'Department of Epidemiology, School of Public Health, Brown University, Providence, RI, USA: ${ }^{2}$ Department of \\ Epidemiology, School of Public Health, University of Michigan, Ann Arbor, MI, USA: ${ }^{3}$ Department of Nutritional \\ Sciences, School of Public Health, University of Michigan, Ann Arbor, MI, USA: ${ }^{4}$ Ministry of Health, Apia, Samoa: \\ ${ }^{5}$ Samoa Bureau of Statistics, Apia, Samoa: ${ }^{6}$ Department of Chronic Disease Epidemiology, School of Public Health, \\ Yale University, 60 College Street, New Haven, CT 06520-8034, USA: ${ }^{7}$ Institute for Physical Activity and Nutrition \\ (IPAN), Deakin University, Geelong, Australia: ${ }^{8}$ Australian Institute for Musculoskeletal Science, St. Albans, \\ Melbourne, Australia
}

Submitted 16 July 2017: Final revision received 17 November 2017: Accepted 27 November 2017: First published online 24 January 2018

\begin{abstract}
Objective: Among young Samoan children, diet may not be optimal: in 2015, 16.1\% of 24-59-month-olds were overweight/obese, $20 \cdot 3 \%$ stunted and $34.1 \%$ anaemic. The present study aimed to identify dietary patterns among 24-59-month-old Samoan children and evaluate their association with: (i) child, maternal and household characteristics; and (ii) nutritional status indicators (stunting, overweight/ obesity, anaemia).

Design: A community-based, cross-sectional study. Principal component analysis on 117 FFQ items was used to identify empirical dietary patterns. Distributions of child, maternal and household characteristics were examined by factor score quintiles. The regression of nutritional status indicators $v$. these quintiles was performed using logistic regression models.

Setting: Ten villages on the Samoan island of Upolu.

Subjects: A convenience sample of mother-child pairs ( $n$ 305).

Results: Two dietary patterns, modern and neo-traditional, emerged. The modern pattern was loaded with 'westernized' foods (red meat, condiments and snacks). The neo-traditional pattern included vegetables, local starches, coconuts, fish and poultry. Following the modern diet was associated with urban residence, greater maternal educational attainment, higher socio-economic status, lower vitamin $\mathrm{C}$ intake and higher sugar intake. Following the neo-traditional diet was associated with rural residence, lower socio-economic status, higher vitamin $\mathrm{C}$ intake and lower sugar intake. While dietary patterns were not related to stunting or anaemia, following the neo-traditional pattern was positively associated with child overweight/obesity (adjusted OR $=4 \cdot 23,95 \%$ CI $1 \cdot 26,14 \cdot 17$, for the highest quintile, $P$-trend $=0 \cdot 06$ ). Conclusions: Further longitudinal monitoring and evaluation of early childhood growth and development are needed to understand the influences of early diet on child health in Samoa.
\end{abstract}

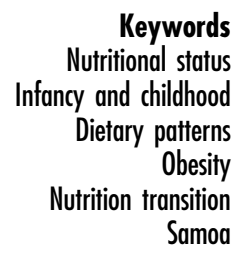

Optimal nutritional intake in early childhood is an important foundation for lifelong health and well-being ${ }^{(1)}$. Appropriate growth and development, which occur more rapidly in the first years of life than during any other period, require adequate intakes of both macronutrients (protein, carbohydrates and fats) and micronutrients

$\dagger$ Courtney C. Choy and Dongqing Wang are co-first authors. (vitamins and minerals) ${ }^{(2)}$. Poor nutritional status may disrupt developmental and biological processes, leading to weakened immune systems, altered brain structures and later impairments in health ${ }^{(3,4)}$. Undernourished children often face an increased risk of infection, experience greater severity of illness and are more likely to die from illness than well-nourished children ${ }^{(5)}$. In low- and middleincome countries undergoing economic development, 
urbanization and the associated nutrition transition, young children face greater exposure to nutrient-poor foods and consequently are particularly vulnerable to non-communicable diseases ${ }^{(6)}$. Concurrent societal shifts towards increased sedentary activity and increased availability of processed, imported foods in the population create an environment that is not conducive for young children to achieve adequate nutritional status ${ }^{(7,8)}$.

Samoa has been experiencing economic and nutrition transition for more than two decades, accompanied by an increasing prevalence of non-communicable diseases ${ }^{(9-12)}$. Among adults, the prevalence of overweight/obesity has risen by more than $20 \%$ over this period ${ }^{(13)}$. Worrisome levels of malnutrition have also been observed among the youngest children in this setting. Our own 2015 survey of child nutritional status documented stunting among $20 \cdot 1 \%$ of Samoan children aged 24-59 months, while $16 \cdot 1 \%$ were overweight/obese and $34.1 \%$ anaemic $^{(14)}$. A dual burden of malnutrition was apparent in these young children, with $28.6 \%$ of overweight/obese children also stunted and $42.9 \%$ anaemic. Among the children classified as stunted, $48.4 \%$ were anaemic. In the same survey, we found that children classified as stunted were less likely to eat frozen desserts regularly, and overweight/obese children had higher intakes of $\mathrm{Ca}$ and lower intakes of sugar (this apparently paradoxical finding is discussed in detail in our earlier publication) ${ }^{(14)}$. While we were able to link these specific individual nutrients/foods with child nutritional status, further exploration of the overall pattern of dietary intake may help to explain the observed burden of malnutrition in this age group.

Dietary patterns among Samoan children remain largely understudied. Studies in 1990-1995 (using principal components analysis (PCA)) ${ }^{(15)}$, 2002-2003 (partial leastsquares regression) ${ }^{(16)}$ and 2010 (PCA $^{(17)}$ documented dietary patterns among Samoan adults and their changes over time. The studies at the two earlier time points identified distinct modern and neo-traditional dietary patterns among Samoan adults and found that the modern pattern was positively associated with adverse metabolic outcomes, whereas inverse associations were present for the neo-traditional pattern ${ }^{(15,16)}$. The more recent data from 2010 revealed that among adults the neo-traditional diet is being replaced by mixed patterns consisting of a combination of modern and neo-traditional foods ${ }^{(17)}$. In other settings, parents and other household members influence the formation of child dietary patterns through decisions about the types of food to offer in the house and enforcing rules related to eating ${ }^{(18,19)}$. Therefore, as family lifestyles change with urbanization and the nutrition transition progresses in Samoa ${ }^{(10)}$, dietary patterns in children may be following the same trajectory of change identified in adults.

Considering that early-life nutrition plays a role in the development of health risks in later life ${ }^{(1,20)}$, contemporary information about dietary patterns and their associated child, maternal and household-level characteristics can provide insights into potential targets for interventions that can encourage healthy eating behaviour. Further utilizing data collected on dietary intake from our 2015 study of nutritional status, the present cross-sectional study investigates dietary patterns among Samoan children between 24 and 59 months old. Our primary aim was to identify dietary patterns of young children and to evaluate their associations with child, maternal and household-level characteristics, and child nutritional status indicators (stunting, overweight/obesity, anaemia). A secondary aim was to characterize macro- and micronutrient intakes associated with each dietary pattern.

\section{Methods}

\section{Study design and participants}

A convenience sample of 305 mother-child pairs from ten villages across the Samoan island of Upolu was recruited between June and August 2015. Limited child health data exist, and so the study was powered to detect an 8-10\% difference in the prevalence of obesity compared with the 1999 Samoa National Nutrition Survey (estimate based on an increase in obesity of over $20 \%$ among adults over the same period). Three hundred mother-child pairs were needed to detect this difference at $80 \%$ power, $\alpha=0 \cdot 10$. A detailed description of the study recruitment strategy has been reported previously ${ }^{(14)}$. Briefly, a central location in each village was selected and village leadership assisted the study team in advertising the study to local mothers. Participation was voluntary and interested participants arrived at the study location on the specified days of the survey. Eligible mothers were not pregnant, had no severe physical or cognitive impairments, and were willing/able to complete the interview portion of the study. Eligible children were 24-59 months old and of Samoan ethnicity (based on the maternal report that the child had four Samoan grandparents). As one of the goals of the original study was to examine variation in health status by varying levels of urbanization and exposure to the nutrition transition, equal numbers of participants were recruited from three regions in Upolu: the Apia urban area (AUA; an urban region with high exposure), Northwest Upolu (NWU; a peri-urban region with moderate exposure) and Rest of Upolu (ROU; a rural region with low exposure). The study was not, therefore, representative of the national population distribution. Compared with the 2014 Samoan Demographic and Health Survey, our mothers were less educated (60.3\% had secondary education $v$. $76 \%$ of the general population) and of slightly lower socio-economic status based on household ownership of consumer durables than the general population in Samoa ${ }^{(21)}$.

\section{Physical measurements and child nutritional status indicators}

Anthropometric measurements were taken from both mothers and children using standardized procedures ${ }^{(22)}$, 
with all participants in light island clothing. Standing height was measured to the nearest $0 \cdot 1 \mathrm{~cm}$ using a portable stadiometer (Pfister Imports, NY, USA) and weight to the nearest $0 \cdot 1 \mathrm{~kg}$ using a Tanita HD 351 digital weight scale (Tanita Corporation of America, IL, USA). Duplicate measures were averaged for use in analyses. Maternal weight status was classified as either normal $\left(<26 \mathrm{~kg} / \mathrm{m}^{2}\right)$ or overweight/obese $\left(\geq 26 \mathrm{~kg} / \mathrm{m}^{2}\right)$ based on Polynesian BMI cut-offs, which are sensitive to the greater lean mass per kilogram in the adult Polynesian population compared with those of other ethnicities ${ }^{(23)}$. A finger-prick blood $\mathrm{Hb}$ sample was taken using an AimStrip $\mathrm{Hb}$ test system (Germaine Laboratories Inc., TX, USA) to indicate presence or absence of anaemia. Maternal anaemia was defined as $\mathrm{Hb}$ less than $12.0 \mathrm{~g} / \mathrm{dl}^{(24)}$ and child anaemia as $\mathrm{Hb}$ below $11.0 \mathrm{~g} / \mathrm{dl}^{(24)}$.

Dichotomous indicators of child stunting and overweight/obesity were constructed according to the 2006 $\mathrm{WHO}^{(24)}$ growth standards. Children whose height-for-age was below -2 SD or whose BMI-for-age was above 2 sD from the corresponding median of the reference population were classified as stunted or overweight/obese, respectively $^{(25)}$. Only seven children were identified as being underweight (weight-for-age below -2 SD of the median weight-for-age of the reference population). Given the small sample size in our study, this outcome was not independently examined, and underweight children were combined with those who were normal weight in further analyses.

\section{Child, maternal and bousebold characteristics}

Detailed information on the child, maternal and household characteristics was obtained through a questionnaire administered in Samoan to all mothers. Child characteristics included health history, infant feeding practices (ever breast-fed was determined by response to a single yes/no question 'Was your child ever breast-fed?') and medication use. We included a dietary screener to assess general dietary behaviours. Mothers were asked to describe how many times she and her child ate specific food groups such as fruits, vegetables and frozen desserts (cakes and ice cream) in the past month and how often they ate breakfast. Child physical activity levels were assessed using the Netherlands Physical Activity Questionnaire for Young Children $^{(26)}$. Without a locally validated physical activity questionnaire, we chose to use this questionnaire because it references the same age group and has been widely used in other settings ${ }^{(26,27)}$. Mothers were asked to describe their child's level of physical activity compared with other children using a series of seven 5-point Likert-scale questions. Answers were summed to calculate a 35-point physical activity score, with a higher score indicating higher levels of activity. Maternal demographic characteristics were collected, including age, the highest level of education attained and marital status. For household characteristics, an 18-point material lifestyle score was calculated based on a summed household assets inventory using the following variables: fridge, freezer, stereo, portable stereo, microwave oven, rice cooker, blender, sewing machine, television, VCR/DVD, couch, washing machine, landline telephone, computer/laptop, tablet, electric fan, air conditioner and motor vehicle. Total annual income of the household, including overseas remittances, was measured using five categories of income based on the 2011 Samoa census $^{(28)}$. Based on the distribution of responses, income was dichotomized into less than 10000 tala (equivalent to less than \$US 4000) and equal to or more than 10000 tala.

\section{Child dietary intake}

Child dietary intake was measured using a 117-item FFQ with a $30 \mathrm{~d}$ reference period. The questionnaire was adapted for the 24-59-month-old age group of interest from an adult FFQ, previously validated for use in the adult Samoan population ${ }^{(16)}$ and used in $2010^{(17)}$, to include three infant-specific food items widely available in Samoa (canned infant foods, puréed fruit/vegetable pouches, infant formula) and breast milk and to remove alcoholic beverages. Mothers were asked how often, on average, their child consumed each food with nine possible responses: '<once/month or never', '1-3 times/month', 'once/week', '2-4 times/week', '5-6 times/week', 'once/ day', '2-3 times/day', '4-5 times/day' and ' $\geq 6$ times/day'. Daily total energy and nutrient intakes were calculated by multiplying the daily consumption frequency of each food by the nutrient content of a fixed, standard portion size, as described previously ${ }^{(14)}$.

\section{Statistical methods}

Distributions of selected child, maternal and householdlevel characteristics were examined by stunting, overweight/obesity and anaemia status to identify potential covariates for subsequent analyses (see online supplementary material, Supplemental Table 1). The differences between those with and without each nutrition outcome were tested with $\chi^{2}$ tests for categorical variables, $t$ tests for normally distributed continuous variables and Wilcoxon rank-sum tests for non-normal continuous variables.

\section{Identification of dietary patterns: principal component analysis}

We used PCA to identify empirical dietary patterns. Based on the need to create normally distributed dietary variables in preparation for energy adjustment ${ }^{(29)}$, the 117 individual food items from the FFQ were put into thirty-five pre-specified nutritionally similar food groups based on culinary use and nutrient profile in Samoan children (see online supplementary material, Supplemental Table 2). For each food group, we summed the frequencies of individual foods, adjusted the sum for total energy intake using the residual method ${ }^{(30)}$ and used the energy-adjusted group frequencies as inputs of PCA. We 
rotated the identified factors by orthogonal transformation to achieve uncorrelated and more interpretable structures. The number of factors retained was based on the scree plot $^{(31)}$, the eigenvalues $>1$ criterion, the proportion of variance explained by each factor and by all factors retained, and the general interpretability of each factor ${ }^{(32)}$. The standardized frequencies of intake for each food group were multiplied by factor score coefficients, and the sum of these products was the factor score for each derived factor. Factor scores of each dietary pattern were categorized into quintiles (chosen to increase the likelihood of depicting a trend $v$. tertiles or quartiles), with every participant being allocated to a quintile for each dietary pattern. Because of the orthogonal transformation in PCA, the dietary patterns were statistically independent of one another. In this way, there would be no mutual confounding among the patterns, so we were able to examine the association between each outcome and each dietary pattern individually. To test the robustness of the identified dietary patterns, we stratified the total sample by sex to derive dietary patterns for boys and girls separately. We also acknowledged that grouping food variables into groups was a subjective procedure. Therefore, we conducted an additional test of robustness/ validity by using the 117 individual food items as inputs of PCA.

\section{Bivariate and multivariate analyses}

Distributions of the child, maternal and household characteristics were examined by quintiles of dietary patterns. The regression of stunting, overweight/obesity and anaemia status $v$. quintiles of factor scores was performed using logistic regression models before and after adjusting for potential confounders. To test for trends across quintiles of dietary patterns, the median value of each quintile was assigned to all participants in the same quintile and treated as a continuous variable in the regression analyses. Child age, sex, total energy intake (continuous) and census region (AUA, NWU, ROU) were included in all models regardless of their statistical significance to ensure that the observed associations were not confounded by these sample characteristics.

We included a covariate into the model as a potential confounder if it satisfied the following criteria: (i) a priori knowledge of child, maternal and household-level risk factors for child nutritional status indicators, supplemented by covariate-exposure associations in our study population; (ii) in bivariate analyses, its association with the dietary pattern was significant at the 0.10 level; (iii) in multivariate analyses, its inclusion changed the OR estimate for at least one quintile level of exposure by $10 \%$ or more after age, sex, total energy intake and census region were included in the model regardless of the $P$ value; and (iv) it was not a mediator. For each indicator of child nutritional status, covariates that did not appreciably change the results were not included in the final logistic regression model (data not shown). The regression of nutritional status indicators $v$. these quintiles was performed using logistic regression models to estimate $\mathrm{OR}$ and $95 \% \mathrm{CI}^{(33)}$. All analyses were conducted using the statistical software package SAS version 9.4, at a two-sided $\alpha$ level of 0.05 .

\section{Results}

\section{Child dietary patterns}

Two child dietary patterns were identified: a modern pattern and a neo-traditional pattern (Table 1). Food groups with factor loadings $\geq 0.3$ or $\leq-0.3$ were flagged as meaningfully contributing to the corresponding dietary pattern. The modern pattern (factor 1 ) was heavily loaded with 'westernized' foods which consisted of unprocessed red meats, whole grains (which are not traditional to Samoa), corn, French fries, butter, mayonnaise, nuts and snack foods like potato chips. The neo-traditional pattern (factor 2) included vegetables, local starchy crops like taro and breadfruit, coconut, fish, poultry and a low intake of desserts, pizza, dairy products (milk, cheese ice cream) and infant food items (infant formula, breast milk, infant packaged food purées and prepared meals). The modern pattern explained $10.7 \%$ of the variation in child diet, while the neo-traditional pattern accounted for a slightly smaller percentage of the variation $(6.3 \%)$.

When we stratified the PCA by sex, and when we used the 117 individual food items as the PCA inputs (data not shown), the modern and neo-traditional patterns were unchanged. We also attempted retaining three factors instead of two, which revealed an 'infant-like' dietary pattern characterized by high intakes of infant food items, dairy products, fruits, potatoes and cereals, along with low intakes of sugary drinks, noodles, fried fish and breadfruit. However, this additional pattern was not robust when individual food items were used in PCA. It also remained present only in girls. As such, the 'infant-like' pattern was not retained in further analyses.

\section{Unadjusted associations between dietary patterns and selected child, maternal and housebold-level characteristics}

Following the modern dietary pattern was associated with living in the urban AUA region (Table $2 ; 44.3 \%$ in AUA $v$. $14.8 \%$ in ROU, compared at the highest factor score quintile, $P<0.001)$. From the first to fifth quintile of the modern dietary factor score, vitamin $\mathrm{C}$ intake decreased by $47 \mathrm{mg} / \mathrm{d}(P=0.020)$ and sugar intake increased by nearly $20 \mathrm{~g} / \mathrm{d}(P=0 \cdot 019)$. Children whose mothers had higher educational attainment (graduated from high school $v$. not) tended to follow the modern pattern $(70.5 \%$ in the highest quintile compared with $44.3 \%$ in the lowest 
Table 1 Factor loadings for child dietary patterns derived from principal component analysis*

\begin{tabular}{|c|c|c|}
\hline & $\begin{array}{l}\text { Factor } 1 \\
\text { (Modern) }\end{array}$ & $\begin{array}{c}\text { Factor } 2 \\
\text { (Neo-traditional) }\end{array}$ \\
\hline Variation explained (\%) & $10 \cdot 7$ & $6 \cdot 3$ \\
\hline \multicolumn{3}{|l|}{ Food groupst } \\
\hline Unprocessed red meat & 0.74 & -0.21 \\
\hline Whole grains & 0.69 & 0.02 \\
\hline Corn & 0.69 & 0.09 \\
\hline French fries & 0.51 & -0.17 \\
\hline Salad dressings & 0.50 & -0.09 \\
\hline Butter & 0.49 & -0.11 \\
\hline Nuts & 0.41 & -0.07 \\
\hline Snacks & 0.41 & -0.13 \\
\hline Margarine & 0.25 & -0.12 \\
\hline Processed red meat & 0.25 & -0.09 \\
\hline Sugary drinks & 0.21 & $0 \cdot 14$ \\
\hline Fruit juices & 0.19 & -0.17 \\
\hline Noodles & 0.11 & $0 \cdot 11$ \\
\hline Fruits & $-0 \cdot 18$ & -0.04 \\
\hline Other fish (not fried) & -0.20 & 0.53 \\
\hline Yam and taro & -0.15 & 0.45 \\
\hline Vegetables & -0.04 & 0.44 \\
\hline Breadfruit & $-0 \cdot 10$ & 0.42 \\
\hline Soup & -0.04 & 0.42 \\
\hline Coconut and coconut products & -0.02 & 0.42 \\
\hline Bananas as staple & $-0 \cdot 16$ & 0.40 \\
\hline Poultry & 0.01 & 0.30 \\
\hline Tomato & -0.03 & 0.29 \\
\hline Tea & 0.01 & 0.26 \\
\hline Fried fish & 0.21 & 0.24 \\
\hline Seafood & -0.01 & 0.20 \\
\hline Eggs & -0.02 & 0.03 \\
\hline Mixed dishes & 0.08 & -0.16 \\
\hline Refined grains & -0.13 & -0.19 \\
\hline Infant food items & -0.05 & -0.31 \\
\hline Sweets or desserts & 0.18 & -0.31 \\
\hline Pizza & 0.14 & -0.33 \\
\hline Potatoes/sweet potatoes & 0.00 & -0.40 \\
\hline Dairy products & 0.04 & -0.43 \\
\hline Cereals & 0.05 & -0.50 \\
\hline
\end{tabular}

*Values are factor loadings or correlations of each food item with the given dietary pattern. Food groups with factor loadings $\geq 0.3$ or $\leq-0.3$ are indicated in bold.

†All food groups were energy-adjusted using the residual method.

quintile, $P=0.025)$. Those living in high socio-economic status households were also more likely to follow the modern pattern, as indicated by material lifestyle score ( 42.6 v. $4.9 \%$ in the highest factor score quintile, $P=0.0015)$ and annual income of 10000 tala or more (26.2\% in the highest quintile compared with $3.3 \%$ in the lowest quintile, $P<0.001$ ).

On the other hand, following the neo-traditional dietary pattern was strongly associated with living in the rural ROU region ( $45.9 \%$ in ROU v. 26.2\% in AUA, compared at the highest factor score quintile, $P=0 \cdot 019)$. Increasing vitamin $\mathrm{C}$ intake was observed with increasing quintile of neo-traditional dietary factor score $(P<0 \cdot 001)$, as was decreasing sugar intake $(P<0 \cdot 001)$. While children who were reported to have had an illness in the past 3 weeks were not likely to follow the neo-traditional pattern $(4.9 \%$ in the highest quintile $v .16 .4 \%$ in the lowest quintile, $P=0.024$ ), those who used deworming medication in the past 3 weeks tended to follow this pattern $(32.8 \%$ in the highest quintile $v \cdot 15 \cdot 3 \%$ in the lowest quintile, $P=0 \cdot 035$ ). Following the neo-traditional pattern was also observed among children living in lower socio-economic status households; those with an annual income less than 10000 tala $(99.4 \%$ in the 5 th quintile, $P<0.001)$ and a lower material lifestyle score $(32.8 \%$ in quartile 1 compared with $1.6 \%$ in quartile 4 , in the fifth factor score quintile, $P<0 \cdot 001)$.

\section{Energy-adjusted associations between nutrient intake and dietary patterns}

Comparing the lowest quintile with the highest, children following the modern pattern had lower daily intakes of total protein, fibre, $\mathrm{K}$ and vitamins $\mathrm{C}$ and $\mathrm{E}$, but had higher intakes of total fat and sugar (Table $3 ; P<0 \cdot 05$ ). Children who were in the highest quintile for the neo-traditional diet had lower daily intakes of total carbohydrates, monounsaturated fat, sugar and Ca compared with those in the lowest quintile, but they had higher daily intakes of total protein, polyunsaturated fat, fibre, $\mathrm{Na}, \mathrm{K}$ and vitamins $\mathrm{A}, \mathrm{C}$ and $\mathrm{E}$ (Table 4). While total energy intake increased by $2804 \mathrm{~kJ} / \mathrm{d}$ between the first and fifth quintile of the neo-traditional dietary factor score, it nearly doubled for the modern dietary factor score (14541 v. $21633 \mathrm{~kJ} / \mathrm{d}$, $P<0 \cdot 001)$.

\section{Energy-adjusted association between dietary patterns and child nutritional status indicators}

After adjusting for potential confounders, stunting and anaemia were not significantly associated with either the modern or the neo-traditional dietary pattern (Table 5; all $P$-trend $>0.05)$. While the modern pattern was not related to overweight/obesity, the fifth quintile of the neo-traditional pattern was significantly associated with higher odds of child overweight/obesity (OR $=3 \cdot 43$, 95\% CI 1.03, 11.39). Although there was no significant linear trend observed between child overweight/obesity and following the neo-traditional pattern $(P$-trend $=0.066)$, an apparent threshold effect between the first and second dietary pattern factor score quintiles suggests that there is a positive but non-linear association between the neo-traditional pattern and obesity.

When we removed total energy intake from the models for overweight/obesity (as a sensitivity analysis to determine the potential effect of energy adjustment on our findings), the adjusted OR (and 95\% CI) for the modern and neo-traditional pattern across the five quintiles were similar to the estimates in Table 5 (data not shown). Therefore, the estimates were not sensitive to the treatment of total energy intake in the model after adjusting for other covariates. To account for the quality of dietary patterns, which can impact weight status independently of the total energy intake, we retained total energy intake in the main analysis. 
Table 2 Selected child, maternal and household-level characteristics by dietary factor score quintile among 305 Samoan children aged 24-59 months from the island of Upolu, June-August 2015

\begin{tabular}{|c|c|c|c|c|c|c|c|c|c|c|c|}
\hline \multirow[b]{2}{*}{ Characteristic* $^{*}$} & \multicolumn{2}{|c|}{$\begin{array}{l}\text { Quintile } 1 \\
(n 61)\end{array}$} & \multicolumn{2}{|c|}{$\begin{array}{l}\text { Quintile } 2 \\
(n 61)\end{array}$} & \multicolumn{2}{|c|}{$\begin{array}{l}\text { Quintile } 3 \\
\quad(n 61)\end{array}$} & \multicolumn{2}{|c|}{$\begin{array}{l}\text { Quintile } 4 \\
\quad(n 61)\end{array}$} & \multicolumn{2}{|c|}{$\begin{array}{l}\text { Quintile } 5 \\
\quad(n 61)\end{array}$} & \multirow[b]{2}{*}{$P+$} \\
\hline & $\%$ or Mean & SD & $\%$ or mean & SD & $\%$ or mean & SD & $\%$ or mean & SD & $\%$ or mean & SD & \\
\hline \multicolumn{12}{|l|}{ Factor 1 (Modern) } \\
\hline \multicolumn{12}{|l|}{ Census region } \\
\hline Apia Urban Area & $27 \cdot 9$ & - & 29.5 & - & $27 \cdot 9$ & - & 34.4 & - & $44 \cdot 3$ & - & $<0.001$ \\
\hline Northwest Upolu & 19.7 & - & $21 \cdot 3$ & - & $44 \cdot 3$ & - & 41.0 & - & $41 \cdot 0$ & - & \\
\hline Rest of Upolu & $52 \cdot 5$ & - & $49 \cdot 2$ & - & $27 \cdot 9$ & - & $24 \cdot 6$ & - & $14 \cdot 8$ & - & \\
\hline \multicolumn{12}{|l|}{ Child } \\
\hline Age (months) & $38 \cdot 3$ & 9.8 & $40 \cdot 8$ & $11 \cdot 0$ & 38.6 & 9.5 & 41.4 & $10 \cdot 8$ & $41 \cdot 0$ & $9 \cdot 7$ & 0.291 \\
\hline Female & $39 \cdot 3$ & - & 52.5 & - & $65 \cdot 6$ & - & $49 \cdot 2$ & - & $36 \cdot 1$ & - & 0.010 \\
\hline Height $(\mathrm{cm})$ & 91.8 & $10 \cdot 9$ & 94.4 & $9 \cdot 1$ & 94.7 & $10 \cdot 2$ & 95.5 & $8 \cdot 7$ & $96 \cdot 6$ & 9.9 & 0.093 \\
\hline Weight (kg) & $14 \cdot 8$ & 3.8 & $15 \cdot 0$ & 2.9 & $15 \cdot 5$ & 3.5 & $15 \cdot 6$ & 2.9 & $16 \cdot 4$ & 3.3 & 0.095 \\
\hline Physical activity score & & & & & & & & & & & 0.101 \\
\hline Tertile $1($ mean $=24 \cdot 1, \mathrm{SD}=3 \cdot 8)$ & $42 \cdot 6$ & - & 29.5 & - & $41 \cdot 0$ & - & $27 \cdot 9$ & - & $37 \cdot 7$ & - & \\
\hline Tertile $2($ mean $=29 \cdot 1, \mathrm{sD}=0.7)$ & $31 \cdot 2$ & - & $21 \cdot 3$ & - & $18 \cdot 0$ & - & $36 \cdot 1$ & - & $31 \cdot 2$ & - & \\
\hline Tertile $3($ mean $=32 \cdot 0, \mathrm{SD}=1 \cdot 2)$ & $26 \cdot 2$ & - & $49 \cdot 2$ & - & $41 \cdot 0$ & - & $36 \cdot 1$ & - & $31 \cdot 2$ & - & \\
\hline Ever breast-fed & 47.5 & - & $75 \cdot 4$ & - & $78 \cdot 7$ & - & 68.9 & - & 70.5 & - & 0.002 \\
\hline Ate daily breakfast & 86.9 & - & 52.5 & - & 47.5 & - & $62 \cdot 3$ & - & $82 \cdot 0$ & - & $<0.001$ \\
\hline Eats weekly frozen desserts & $55 \cdot 7$ & - & $75 \cdot 4$ & - & $85 \cdot 3$ & - & 83.6 & - & 83.6 & - & $<0.001$ \\
\hline Illness in the past 3 weeks & 11.5 & - & 11.5 & - & 4.9 & - & $9 \cdot 8$ & - & 9.8 & - & 0.725 \\
\hline $\begin{array}{l}\text { Deworming medication use in the past } \\
3 \text { weeks }\end{array}$ & $24 \cdot 6$ & - & $13 \cdot 1$ & - & $8 \cdot 2$ & - & $18 \cdot 3$ & - & 33.9 & - & 0.004 \\
\hline Mother & & & & & & & & & & & \\
\hline Age (years) & $34 \cdot 4$ & $9 \cdot 7$ & 31.4 & 8.8 & $35 \cdot 1$ & $9 \cdot 6$ & 33.4 & $10 \cdot 2$ & 34.9 & 9.5 & 0.193 \\
\hline Overweight/obesity & $86 \cdot 9$ & - & $82 \cdot 0$ & - & 88.5 & - & $86 \cdot 9$ & - & $91 \cdot 8$ & - & 0.598 \\
\hline Any anaemia & 29.5 & - & $27 \cdot 9$ & - & $19 \cdot 7$ & - & $18 \cdot 0$ & - & $18 \cdot 3$ & - & 0.371 \\
\hline High school graduate & $44 \cdot 3$ & - & $55 \cdot 7$ & - & $65 \cdot 6$ & - & $65 \cdot 6$ & - & 70.5 & - & 0.025 \\
\hline Married or cohabitating & 70.5 & - & $78 \cdot 7$ & - & 83.6 & - & 75.4 & - & $72 \cdot 1$ & - & 0.447 \\
\hline Household & & & & & & & & & & & \\
\hline Material lifestyle score & & & & & & & & & & & 0.002 \\
\hline Quartile $1($ mean $=1 \cdot 3, \mathrm{SD}=0.8)$ & $23 \cdot 0$ & - & $27 \cdot 9$ & - & $19 \cdot 7$ & - & $27 \cdot 9$ & - & 4.9 & - & \\
\hline Quartile $2($ mean $=3.5, \mathrm{sD}=0.5)$ & $34 \cdot 4$ & - & $26 \cdot 2$ & - & $14 \cdot 8$ & - & $18 \cdot 0$ & - & $18 \cdot 0$ & - & \\
\hline Quartile $3($ mean $=5 \cdot 9, \mathrm{SD}=0.8)$ & $31 \cdot 2$ & - & $26 \cdot 2$ & - & $36 \cdot 1$ & - & $31 \cdot 2$ & - & $34 \cdot 4$ & - & \\
\hline Quartile $4($ mean $=10.5, S D=2.8)$ & 11.5 & - & $19 \cdot 7$ & - & 29.5 & - & $23 \cdot 0$ & - & $42 \cdot 6$ & - & \\
\hline Annual income $\geq 10000$ tala & 3.3 & - & $16 \cdot 4$ & - & $30 \cdot 0$ & - & $32 \cdot 8$ & - & $26 \cdot 2$ & - & $<0.001$ \\
\hline Factor 2 (Neo-traditional) & & & & & & & & & & & \\
\hline Census region & & & & & & & & & & & \\
\hline Apia Urban Area & $39 \cdot 3$ & - & $47 \cdot 5$ & - & $29 \cdot 5$ & - & $21 \cdot 3$ & - & $26 \cdot 2$ & - & 0.019 \\
\hline Northwest Upolu & $34 \cdot 4$ & - & $21 \cdot 3$ & - & $41 \cdot 0$ & - & $42 \cdot 6$ & - & 27.9 & - & \\
\hline Rest of Upolu & $26 \cdot 2$ & - & $31 \cdot 2$ & - & 29.5 & - & $36 \cdot 1$ & - & 45.9 & - & \\
\hline Child & & & & & & & & & & & \\
\hline Age (months) & $39 \cdot 0$ & $10 \cdot 3$ & $40 \cdot 6$ & $11 \cdot 2$ & $39 \cdot 8$ & $9 \cdot 8$ & $41 \cdot 6$ & $9 \cdot 8$ & $39 \cdot 2$ & $10 \cdot 0$ & 0.614 \\
\hline Female & $36 \cdot 1$ & - & $49 \cdot 2$ & - & $55 \cdot 7$ & - & $55 \cdot 7$ & - & 45.9 & - & 0.164 \\
\hline Height (cm) & 94.5 & $10 \cdot 1$ & $95 \cdot 8$ & $10 \cdot 2$ & $94 \cdot 8$ & $9 \cdot 0$ & 94.9 & 9.5 & $93 \cdot 1$ & $10 \cdot 6$ & 0.664 \\
\hline Weight (kg) & $15 \cdot 2$ & $3 \cdot 0$ & $16 \cdot 0$ & 3.5 & $15 \cdot 6$ & $3 \cdot 2$ & $15 \cdot 4$ & $3 \cdot 1$ & $15 \cdot 1$ & 3.7 & 0.643 \\
\hline Physical activity score & & & & & & & & & & & 0.208 \\
\hline Tertile $1($ mean $=24 \cdot 1, \mathrm{SD}=3 \cdot 8)$ & $31 \cdot 2$ & - & $41 \cdot 0$ & - & $24 \cdot 6$ & - & $36 \cdot 1$ & - & 45.9 & - & \\
\hline Tertile $2($ mean $=29.1, \mathrm{SD}=0.7)$ & $31 \cdot 2$ & - & $21 \cdot 3$ & - & $26 \cdot 2$ & - & $31 \cdot 2$ & - & 27.9 & - & \\
\hline Tertile $3($ mean $=32 \cdot 0, \mathrm{SD}=1 \cdot 2)$ & $37 \cdot 7$ & - & $37 \cdot 7$ & - & $49 \cdot 2$ & - & $32 \cdot 8$ & - & $26 \cdot 2$ & - & \\
\hline Ever breast-fed & $57 \cdot 4$ & - & $72 \cdot 1$ & - & $75 \cdot 4$ & - & $67 \cdot 2$ & - & 68.9 & - & 0.265 \\
\hline Ate daily breakfast & $59 \cdot 0$ & - & $55 \cdot 7$ & - & $59 \cdot 0$ & - & $70 . \overline{5}$ & - & 86.9 & - & 0.001 \\
\hline Eats weekly frozen desserts & 83.6 & - & $91 \cdot 8$ & - & $78 \cdot 7$ & - & 68.9 & - & $60 \cdot 7$ & - & $<0.001$ \\
\hline Illness in the past 3 weeks & $16 \cdot 4$ & - & $14 \cdot 8$ & - & $9 \cdot 8$ & - & 1.6 & - & 4.9 & - & 0.024 \\
\hline $\begin{array}{l}\text { Deworming medication use in the past } \\
3 \text { weeks }\end{array}$ & $15 \cdot 3$ & - & $11 \cdot 7$ & - & $16 \cdot 4$ & - & $21 \cdot 3$ & - & $32 \cdot 8$ & - & 0.035 \\
\hline Mother & & & & & & & & & & & \\
\hline Age (years) & 33.3 & $9 \cdot 7$ & $35 \cdot 4$ & 9.9 & $31 \cdot 7$ & $9 \cdot 7$ & $33 \cdot 1$ & $8 \cdot 2$ & $35 \cdot 7$ & $10 \cdot 2$ & 0.123 \\
\hline Overweight/obesity & $85 \cdot 3$ & - & 88.5 & - & $85 \cdot 3$ & - & $85 \cdot 3$ & - & $91 \cdot 8$ & - & 0.758 \\
\hline Any anaemia & $16 \cdot 4$ & - & $20 \cdot 0$ & - & $36 \cdot 1$ & - & $14 \cdot 8$ & - & $26 \cdot 2$ & - & 0.033 \\
\hline High school graduate & 73.8 & - & $59 \cdot 0$ & - & 63.9 & - & 52.5 & - & 52.5 & - & 0.087 \\
\hline Married or cohabitating & $77 \cdot 1$ & - & 68.9 & - & 86.9 & - & $77 \cdot 1$ & - & 70.5 & - & 0.149 \\
\hline Household & & & & & & & & & & & \\
\hline Material lifestyle score & & & & & & & & & & & $<0.001$ \\
\hline Quartile $1($ mean $=1.3, \mathrm{sD}=0.8)$ & $3 \cdot 3$ & - & $14 \cdot 8$ & - & $8 \cdot 2$ & - & $44 \cdot 3$ & - & $32 \cdot 8$ & - & \\
\hline Quartile $2($ mean $=3.5, \mathrm{sD}=0.5)$ & $13 \cdot 1$ & - & $18 \cdot 0$ & - & $19 \cdot 7$ & - & $31 \cdot 2$ & - & 29.5 & - & \\
\hline Quartile $3($ mean $=5.9, \mathrm{sD}=0.8)$ & $39 \cdot 3$ & - & $27 \cdot 9$ & - & $44 \cdot 3$ & - & $16 \cdot 4$ & - & $31 \cdot 2$ & - & \\
\hline Quartile $4($ mean $=10.5, \mathrm{SD}=2.8)$ & $44 \cdot 3$ & - & $39 \cdot 3$ & - & $27 \cdot 9$ & - & 8.2 & - & $6 \cdot 6$ & - & \\
\hline Annual income $\geq 10000$ tala & $39 \cdot 3$ & - & $32 \cdot 8$ & - & $30 \cdot 0$ & - & 4.9 & - & 1.6 & - & $<0.001$ \\
\hline
\end{tabular}

*One missing value for maternal anaemia and household annual income, and three missing values for deworming medication use.

$\dagger P$ values report significance of between-quintile ANOVA for continuous variables and $x^{2}$ tests for categorical variables. Significant $P$ values are indicated in bold. 
Table 3 Energy-adjusted daily macronutrient and micronutrient intakes by dietary factor 1 (modern) score quintile among the 305 Samoan children aged $24-59$ months from the island of Upolu, June-August 2015

\begin{tabular}{|c|c|c|c|c|c|c|c|c|c|c|c|}
\hline \multirow[b]{2}{*}{ Characteristic } & \multicolumn{2}{|c|}{$\begin{array}{l}\text { Quintile } 1 \\
\qquad(n \text { 61) }\end{array}$} & \multicolumn{2}{|c|}{$\begin{array}{l}\text { Quintile } 2 \\
\quad(n \text { 61) }\end{array}$} & \multicolumn{2}{|c|}{$\begin{array}{l}\text { Quintile } 3 \\
\text { (n 61) }\end{array}$} & \multicolumn{2}{|c|}{$\begin{array}{c}\text { Quintile } 4 \\
\quad(n 61)\end{array}$} & \multicolumn{2}{|c|}{$\begin{array}{l}\text { Quintile } 5 \\
\quad(n 61)\end{array}$} & \multirow[b]{2}{*}{$P^{*}$} \\
\hline & Mean & SD & Mean & SD & Mean & SD & Mean & SD & Mean & SD & \\
\hline Total energy intake (kJ) & 14541.5 & 7204.9 & 9645.5 & $7681 \cdot 7$ & 9621.6 & 7534.5 & $15050 \cdot 6$ & 11857.7 & 21633.1 & $14085 \cdot 3$ & $<0.001$ \\
\hline Total protein $(\mathrm{g})$ & $105 \cdot 3$ & 28.1 & 97.8 & 19.7 & 94.7 & 18.8 & 90.4 & 17.8 & 89.8 & 19.0 & $<0.001$ \\
\hline Total carbohydrate $(\mathrm{g})$ & 351.4 & $56 \cdot 2$ & 347.7 & 34.8 & 349.7 & 32.0 & 353.7 & $38 \cdot 3$ & 349.2 & 39.8 & 0.943 \\
\hline Total fat (g) & 98.0 & 13.7 & 103.5 & 9.0 & 104.2 & 9.8 & 105.9 & 11.4 & 108.5 & 11.6 & $<0.001$ \\
\hline Saturated fat $(\mathrm{g})$ & $46 \cdot 3$ & 10.5 & $45 \cdot 2$ & 7.0 & 44.9 & 6.9 & 46.5 & 9.5 & 46.9 & 8.4 & 0.635 \\
\hline Monounsaturated fat $(\mathrm{g})$ & $25 \cdot 3$ & 6.6 & $28 \cdot 6$ & $5 \cdot 2$ & 29.5 & 5.2 & $30 \cdot 3$ & $6 \cdot 3$ & 32.1 & 7.1 & $<0.001$ \\
\hline Polyunsaturated fat $(\mathrm{g})$ & 14.5 & 3.9 & 16.5 & 2.7 & $16 \cdot 5$ & 3.4 & 17.0 & 3.5 & 18.0 & 3.8 & $<0.001$ \\
\hline Fibre (g) & 37.7 & 9.0 & 37.7 & $7 \cdot 7$ & $37 \cdot 1$ & 7.4 & 35.2 & $6 \cdot 3$ & 33.4 & 6.5 & 0.005 \\
\hline Cholesterol (mg) & 374.0 & 141.0 & $356 \cdot 6$ & 144.6 & $363 \cdot 3$ & $115 \cdot 3$ & 365.2 & $111 \cdot 1$ & 364.0 & 105.5 & 0.962 \\
\hline Sugar intake (g) & 133.5 & 43.4 & 144.0 & 31.3 & $149 \cdot 6$ & $28 \cdot 3$ & 150.7 & 32.6 & $150 \cdot 3$ & 40.4 & 0.040 \\
\hline $\mathrm{Na}(\mathrm{mg})$ & $3006 \cdot 9$ & 734.1 & $3127 \cdot 2$ & 568.9 & 3184.0 & 568.0 & $3168 \cdot 8$ & $545 \cdot 0$ & 3221.6 & $713 \cdot 1$ & 0.384 \\
\hline $\mathrm{K}(\mathrm{mg})$ & $5026 \cdot 6$ & 857.6 & 4709.0 & 799.2 & $4614 \cdot 1$ & 744.7 & 4434.1 & 672.7 & $4230 \cdot 2$ & $767 \cdot 3$ & $<0.001$ \\
\hline $\mathrm{Fe}(\mathrm{mg})$ & 15.9 & 2.6 & $16 \cdot 6$ & $2 \cdot 2$ & 16.9 & 2.6 & $16 \cdot 8$ & 2.0 & $16 \cdot 8$ & 2.1 & 0.092 \\
\hline $\mathrm{Ca}(\mathrm{mg})$ & 784.4 & 302.5 & $736 \cdot 6$ & 168.9 & 765.4 & $149 \cdot 2$ & 745.8 & 156.7 & 746.4 & 155.1 & 0.672 \\
\hline Vitamin A (IU) & $2765 \cdot 2$ & 2037.6 & 2532.8 & $1905 \cdot 7$ & 2793.9 & 1649.6 & $2360 \cdot 1$ & 1439.4 & 2639.4 & $1719 \cdot 2$ & 0.647 \\
\hline Vitamin $A$, retinol $(\mu \mathrm{g})$ & $829 \cdot 6$ & 611.3 & 759.8 & 571.7 & 838.2 & 494.9 & 708.0 & 431.8 & 791.8 & $515 \cdot 8$ & 0.647 \\
\hline Vitamin $A, \beta$-carotene $(\mu \mathrm{g})$ & $1659 \cdot 1$ & 1222.6 & 1519.7 & 1143.4 & $1676 \cdot 3$ & 989.8 & $1416 \cdot 1$ & 863.6 & $1583 \cdot 6$ & 1031.5 & 0.647 \\
\hline Vitamin C (mg) & 274.1 & $126 \cdot 2$ & 257.5 & 80.3 & 242.1 & 63.2 & 234.2 & 68.4 & 229.1 & 77.5 & 0.027 \\
\hline Vitamin E (mg) & 12.4 & 2.9 & 12.0 & 2.4 & 11.7 & 2.9 & 11.2 & $2 \cdot 6$ & $11 \cdot 1$ & 2.5 & 0.034 \\
\hline
\end{tabular}

${ }^{*} P$ values report significance of between-quintile ANOVA. Significant $P$ values are indicated in bold.

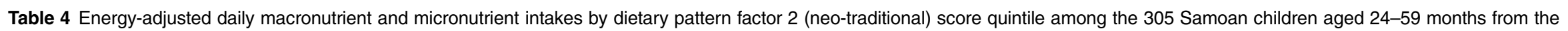
island of Upolu, June-August 2015

\begin{tabular}{|c|c|c|c|c|c|c|c|c|c|c|c|}
\hline \multirow[b]{2}{*}{ Characteristic } & \multicolumn{2}{|c|}{ Quintile 1 ( $n$ 61) } & \multicolumn{2}{|c|}{ Quintile 2 ( $n$ 61) } & \multicolumn{2}{|c|}{ Quintile 3 ( $n$ 61) } & \multicolumn{2}{|c|}{ Quintile 4 ( $n$ 61) } & \multicolumn{2}{|c|}{ Quintile 5 ( $n$ 61) } & \multirow[b]{2}{*}{$P^{\star}$} \\
\hline & Mean & SD & Mean & SD & Mean & SD & Mean & SD & Mean & SD & \\
\hline Total energy intake (kJ) & $15232 \cdot 6$ & 12386.8 & $8865 \cdot 2$ & 5659.4 & $13258 \cdot 3$ & $12319 \cdot 1$ & $15099 \cdot 2$ & $11277 \cdot 1$ & 18036.9 & $9747 \cdot 2$ & $<0.001$ \\
\hline Total protein $(\mathrm{g})$ & $83 \cdot 6$ & $16 \cdot 8$ & $90 \cdot 3$ & 14.7 & 89.6 & $17 \cdot 0$ & 99.6 & 18.7 & 114.9 & $25 \cdot 1$ & $<0.001$ \\
\hline Total carbohydrate $(\mathrm{g})$ & 364.4 & 39.4 & 349.8 & 30.5 & 358.7 & 34.1 & 347.0 & $40 \cdot 8$ & 331.7 & $50 \cdot 2$ & $<0.001$ \\
\hline Total fat $(\mathrm{g})$ & $104 \cdot 0$ & 11.9 & $106 \cdot 3$ & $10 \cdot 0$ & 103.5 & 9.5 & $104 \cdot 2$ & 11.5 & $102 \cdot 2$ & 14.7 & 0.425 \\
\hline Saturated fat (g) & $46 \cdot 3$ & 6.5 & $45 \cdot 0$ & $7 \cdot 0$ & 46.5 & 8.4 & $46 \cdot 3$ & $7 \cdot 7$ & $45 \cdot 8$ & $12 \cdot 2$ & 0.871 \\
\hline Monounsaturated fat (g) & 31.3 & 6.9 & 31.8 & 6.6 & $28 \cdot 1$ & 4.8 & 28.8 & 5.4 & $25 \cdot 9$ & 6.7 & $<0.001$ \\
\hline Polyunsaturated fat (g) & $15 \cdot 9$ & 4.3 & $17 \cdot 6$ & $2 \cdot 7$ & $15 \cdot 3$ & $2 \cdot 8$ & $17 \cdot 0$ & $3 \cdot 2$ & $16 \cdot 6$ & 4.5 & 0.006 \\
\hline Fibre (g) & 30.9 & $6 \cdot 4$ & 33.3 & $5 \cdot 1$ & 37.9 & $5 \cdot 0$ & 38.7 & 6.5 & $40 \cdot 4$ & 9.6 & $<0.001$ \\
\hline Cholesterol (mg) & 332.7 & 88.8 & 359.8 & $95 \cdot 1$ & 353.4 & 122.9 & 385.6 & 137.7 & $391 \cdot 6$ & $156 \cdot 1$ & 0.053 \\
\hline Sugar intake $(\mathrm{g})$ & $163 \cdot 3$ & 38.3 & $150 \cdot 2$ & $27 \cdot 7$ & 153.6 & 37.6 & $142 \cdot 3$ & $28 \cdot 0$ & $118 \cdot 7$ & 31.4 & $<0.001$ \\
\hline $\mathrm{Na}(\mathrm{mg})$ & $3004 \cdot 9$ & 687.4 & 3063.5 & $479 \cdot 6$ & $3017 \cdot 7$ & $487 \cdot 2$ & $3234 \cdot 1$ & $504 \cdot 1$ & $3388 \cdot 2$ & $844 \cdot 3$ & 0.002 \\
\hline $\mathrm{K}(\mathrm{mg})$ & $3844 \cdot 2$ & 577.3 & 4138.5 & 386.5 & $4550 \cdot 3$ & 437.0 & $4926 \cdot 8$ & 559.9 & 5554.1 & $716 \cdot 6$ & $<0.001$ \\
\hline $\mathrm{Fe}(\mathrm{mg})$ & $17 \cdot 1$ & $2 \cdot 8$ & $17 \cdot 0$ & 2.5 & $16 \cdot 3$ & 1.9 & $16 \cdot 2$ & 1.9 & 16.5 & 2.4 & 0.068 \\
\hline $\mathrm{Ca}(\mathrm{mg})$ & 820.5 & 247.2 & 724.8 & $125 \cdot 0$ & 757.1 & 129.4 & 757.6 & $187 \cdot 3$ & $718 \cdot 4$ & 239.2 & 0.031 \\
\hline Vitamin A (IU) & $1840 \cdot 3$ & $1265 \cdot 7$ & $1961 \cdot 4$ & 1137.8 & $2743 \cdot 3$ & $1264 \cdot 2$ & $2717 \cdot 3$ & 1383.1 & 3829.0 & $2585 \cdot 2$ & $<0.001$ \\
\hline Vitamin A, retinol $(\mu \mathrm{g})$ & $552 \cdot 1$ & 379.7 & 588.4 & $341 \cdot 3$ & 823.0 & $379 \cdot 3$ & $815 \cdot 2$ & 414.9 & $1148 \cdot 7$ & $775 \cdot 6$ & $<0.001$ \\
\hline Vitamin $A, \beta$-carotene $(\mu \mathrm{g})$ & $1104 \cdot 2$ & 759.4 & $1176 \cdot 8$ & 682.7 & $1646 \cdot 0$ & 758.5 & $1630 \cdot 4$ & 829.9 & 2297.4 & $1551 \cdot 1$ & $<0.001$ \\
\hline Vitamin C (mg) & $220 \cdot 8$ & $102 \cdot 1$ & $218 \cdot 9$ & $49 \cdot 5$ & 251.7 & $72 \cdot 1$ & 270.5 & $89 \cdot 2$ & $275 \cdot 2$ & 97.4 & $<0.001$ \\
\hline Vitamin E (mg) & 9.7 & $2 \cdot 2$ & $11 \cdot 0$ & 2.5 & 11.5 & $2 \cdot 1$ & $12 \cdot 1$ & 1.7 & $14 \cdot 0$ & $2 \cdot 9$ & $<0.001$ \\
\hline
\end{tabular}

${ }^{*} P$ values report significance of between-quintile ANOVA. Significant $P$ values are indicated in bold. 
Table 5 OR (and $95 \% \mathrm{Cl}$ ) of child stunting, overweight/obesity and anaemia by dietary pattern factor score quintile among the 305 Samoan children aged 24-59 months from the island of Upolu, June-August 2015

\begin{tabular}{|c|c|c|c|c|c|c|c|c|c|c|}
\hline \multirow[b]{2}{*}{ Model } & \multirow[b]{2}{*}{ Quintile 1 (n 61) } & \multicolumn{2}{|c|}{$\begin{array}{l}\text { Quintile } 2 \\
\text { (n 61) }\end{array}$} & \multicolumn{2}{|c|}{$\begin{array}{l}\text { Quintile } 3 \\
\text { (n61) }\end{array}$} & \multicolumn{2}{|c|}{$\begin{array}{l}\text { Quintile } 4 \\
\quad(n 61)\end{array}$} & \multicolumn{2}{|c|}{$\begin{array}{l}\text { Quintile } 5 \\
\text { (n61) }\end{array}$} & \multirow[b]{2}{*}{$P$-trend ${ }^{*}$} \\
\hline & & OR & $95 \% \mathrm{Cl}$ & OR & $95 \% \mathrm{Cl}$ & OR & $95 \% \mathrm{Cl}$ & OR & $95 \% \mathrm{Cl}$ & \\
\hline \multicolumn{11}{|c|}{ Stunting $(n$ 62)† } \\
\hline \multicolumn{11}{|c|}{ Modern } \\
\hline Crude & Reference & 0.35 & $0.15,0.82$ & 0.43 & $0.19,0.99$ & 0.16 & $0.06,0.45$ & 0.48 & $0.22,1.07$ & 0.123 \\
\hline Adjusted & Reference & 0.60 & $0.22,1.65$ & 1.08 & $0.38,3.09$ & 0.32 & $0.10,1.04$ & 1.08 & $0.39,2.95$ & 0.950 \\
\hline \multicolumn{11}{|c|}{ Neo-traditional } \\
\hline Crude & Reference & 1.79 & $0.69,4.70$ & 1.46 & $0.54,3.92$ & $2 \cdot 16$ & $0.84,5.56$ & $2 \cdot 16$ & $0.84,5.56$ & 0.118 \\
\hline Adjusted & Reference & $2 \cdot 61$ & $0.86,7.93$ & 1.48 & $0.48,4.62$ & 2.17 & $0.71,6.59$ & 1.18 & $0.38,3.62$ & 0.933 \\
\hline \multicolumn{11}{|c|}{ Overweight/obesity ( $n$ 49) $\ddagger$} \\
\hline \multicolumn{11}{|l|}{ Modern } \\
\hline Crude & Reference & 0.46 & $0.15,1.42$ & 1.66 & $0.68,4.07$ & 0.88 & $0.33,2.35$ & 1.00 & $0 \cdot 38,2 \cdot 61$ & $0 \cdot 810$ \\
\hline Adjusted & Reference & 0.49 & $0.15,1.60$ & 1.94 & $0.71,5.29$ & 0.98 & $0.35,2.77$ & 0.71 & $0.24,2.08$ & 0.606 \\
\hline \multicolumn{11}{|c|}{ Neo-traditional } \\
\hline Crude & Reference & 2.48 & $0.88,7.04$ & 1.80 & $0.61,5.30$ & 1.80 & $0.61,5 \cdot 30$ & 1.80 & $0 \cdot 61,5 \cdot 30$ & 0.597 \\
\hline Adjusted & Reference & 3.03 & $1.01,9.07$ & 2.54 & $0.82,7.86$ & 4.23 & $1.26,14 \cdot 17$ & 3.43 & $1.03,11.39$ & 0.066 \\
\hline \multicolumn{11}{|c|}{ Anaemia $(n$ 104)§ } \\
\hline \multicolumn{11}{|c|}{ Modern } \\
\hline Crude & Reference & 1.42 & $0.68,2.94$ & 0.74 & $0.34,1.59$ & 0.62 & $0.28,1.36$ & 1.32 & $0.64,2.76$ & 0.697 \\
\hline Adjusted & Reference & 1.89 & $0.83,4.30$ & 1.05 & $0.43,2.55$ & 0.80 & $0.33,1.91$ & 1.80 & $0.77,4.20$ & 0.367 \\
\hline \multicolumn{11}{|c|}{ Neo-traditional } \\
\hline Crude & Reference & 1.33 & $0.63,2.79$ & 1.08 & $0.51,2.28$ & 1.16 & $0.55,2.44$ & 0.79 & $0.37,1.72$ & 0.431 \\
\hline Adjusted & Reference & 1.47 & $0.63,3.40$ & 0.93 & $0.41,2.15$ & 1.20 & $0.52,2.77$ & 0.55 & $0.23,1.33$ & 0.150 \\
\hline
\end{tabular}

*The median factor score of each quintile was assigned to all participants in the same quintile and treated as a continuous variable in the model. The $P$ value of this continuous variable is the $P$-trend.

†Adjusted for child age, sex, total energy intake, census region (Apia Urban Area, Northwest Upolu, Rest of Upolu), ever breast-fed, having breakfast daily, eating frozen desserts weekly, maternal overweight/obesity, maternal anaemia, maternal education (high school graduate or not) and household annual income ( $\geq 10000$ tala or not). One value is missing for household income and one value is missing for maternal anaemia status.

$\ddagger$ Adjusted for child age, sex, total energy intake, census region (Apia Urban Area, Northwest Upolu, Rest of Upolu) and material lifestyle score (quartiles). $\S$ Adjusted for child age, sex, total energy intake, census region (Apia Urban Area, Northwest Upolu, Rest of Upolu), eating frozen desserts weekly, illness in the past 3 weeks, deworming medication use in the past 3 weeks, maternal age, maternal anaemia and maternal marital status (married/cohabitating or not). One value is missing for maternal anaemia status and three values are missing for deworming medication use.

\section{Discussion}

The present cross-sectional study conducted in 2015 was part of recent efforts to understand the current nutritional status of young children and the early determinants of health in Samoa. As malnutrition and diet-related non-communicable diseases appear to be established in early childhood, it is important to investigate the influence of diet on nutritional status indicators.

We identified two distinct young child dietary patterns. The modern pattern was loaded with 'westernized' foods including red meat, whole grains, condiments and snacks. The neo-traditional pattern included vegetables, fish, poultry, local starchy foods including taro and coconut, and low intakes of dairy products, desserts and infant food items. Both patterns are similar to those previously described among Samoan adults. Until recently, the adult modern pattern in Samoa has been consistently characterized by high intake of westernized foods like milk, cheese and eggs, while the neo-traditional pattern had high loadings of local foods including coconut products and taro ${ }^{(15,16)}$. Interestingly, the mixed-modern and mixed-traditional patterns, containing combinations of modern and traditional foods, identified in Samoan adults most recently $(2010)^{(17)}$, were not observed among the children in our study population. This discrepancy may be explained by the fact that there are certain foods in Samoa that are considered more suitable for children than for adults to protect the growing body from ailments ${ }^{(34)}$. Continuing to grow in an environment with an increasing availability of non-traditional foods ${ }^{(35,36)}$, the eating behaviours of these children may shift towards an adult mixed pattern over time. Longitudinal assessment of dietary intake is needed to identify and monitor changes in dietary patterns with increasing age.

Comparing our findings with other studies is complex because of limited information about dietary patterns among Pacific Island children, variability in types of food available across countries and multiple methodological approaches to identifying dietary patterns ${ }^{(36,37)}$. Among 3.5-7-year-old children in New Zealand, three dietary patterns were identified: a 'healthy' diet (comparable to our neo-traditional diet) with high loadings of fruit, fish and vegetables; a 'junk' diet including candy bars, hamburgers, soft drinks and chips; and a 'traditional' diet distinguished with cauliflower, peas, other mixed vegetables, potatoes, pumpkin and beef as a main dish ${ }^{(38)}$. The Avon Longitudinal Study of Pregnancy and Childhood in the UK identified similar patterns at 4 and 7 years of age: a 'traditional' pattern characterized by meat and vegetables; a 'junk' pattern characterized by high-fat processed foods and snacks (similar to our identified modern pattern); and a 
'health conscious' pattern rich in vegetarian-style foods, rice, pasta, fruit, cheese and fish ${ }^{(39)}$.

In our study, following the modern dietary pattern was associated with greater maternal educational attainment. In contrast, previous studies in developed-country settings have found that pre-school children of mothers with higher education had a diet higher in fruits, vegetables and other nutrient-rich foods ${ }^{(38,40,41)}$. Given the stage of Samoa's economic transition, we believe our findings are plausible; economic transition often impacts higher educated households first, increasing disposable income and allowing access to a greater range of imported, processed, nutrient-poor foods, leading to nutritional and epidemiological transition also occurring first in these households. Later in the transition or after it has occurred (as in the developed-country settings described above) those with higher education are often more likely to adopt healthful behaviours and we may expect to see this pattern emerge in the future as the economic and nutritional transitions progress $^{(6,8)}$.

Indeed, household socio-economic status indicators, including census region of residence, annual income and material lifestyle score, were strongly correlated with the dietary patterns identified. Young Samoan children living in higher socio-economic status households were more likely to have diets that resembled the modern pattern, while those living in the lower socio-economic status households tended to follow the neo-traditional pattern, suggesting urbanization and greater exposure to the nutrition transition have propelled the modernization of the Samoan diet.

To our surprise, being in the highest quintile of the neo-traditional dietary pattern was positively associated with overweight/obesity among the 24-59-month-old children, contradicting existing literature from other low- and middleincome settings ${ }^{(42,43)}$. We suspected that this might reflect the high complex carbohydrate composition of traditional foods such as taro, breadfruit and bananas, and the high saturated fat content of coconut products and locally available poultry (often imported, high-fat cuts) $)^{(33)}$. However, when we conducted additional analyses to explore nutrient intakes by quintile of each dietary pattern, we did not see evidence for this hypothesis. The positive association between following the neo-traditional pattern and child overweight/obesity requires further and longitudinal investigation. Common preparations of local traditional foods, such as vegetables, taro or soups, use coconut cream, added salt and cooking oils, that were not accounted for in the FFQ, all of which may impact the nutritional value of these foods ${ }^{(34)}$.

National nutrition guidance in Samoa encourages a balanced diet consisting of a variety of fresh, local foods, and local health professionals are focusing heavily on promoting a return to traditional diets as a means to counteract the rising prevalence of adult non-communicable diseases. While our data appear to contradict this advice, we suggest that a continued focus on a variety of local, traditional foods is, in fact, the correct approach, so long as attention is paid to both appropriate portion size for age (particularly with regard to root crops high in complex carbohydrates) and food preparation methods. Considering that diet and the home environment in early childhood can influence current and future health ${ }^{(1,44-46)}$, it is important to promote a nutrient-rich, balanced diet within families to prevent and control risk factors for non-communicable diseases among young children.

While the modern pattern was not associated with overweight/obesity, our unadjusted analyses did show that children who followed the modern pattern more closely had a higher intake of sugar and a lower intake of vitamin C than those who did not. In addition, while there was a difference in mean daily energy intake of less than $3000 \mathrm{~kJ}$ between the first and fifth quintiles of the neo-traditional pattern, it increased by over $6000 \mathrm{~kJ}$ between the first and fifth quintiles of the modern pattern. Several food groups within this dietary pattern have been associated with adverse health outcomes in young children in other settings. Among children of pre-school age, dietary patterns characterized by animal products or meat were positively associated with overweight in Korea ${ }^{(42)}$ and Ukraine ${ }^{(43)}$. Another study observed an association between a 'snacky' dietary pattern, high in salty snacks, fat and sugar, and lower scores in verbal and cognitive scales among 4-year-old pre-school children in Crete ${ }^{(47)}$. We suggest, therefore, that continuing to follow the modern pattern may become more problematic over time. Again, longitudinal, rather than cross-sectional analyses, are needed to determine the true impact of both these patterns on growth and health during childhood in this setting.

Neither dietary pattern was significantly associated with either stunting or anaemia. For both stunting and anaemia, underlying infectious disease might impede an accurate assessment of the impact of dietary patterns on these child nutritional status indicators ${ }^{(48)}$. Hookworm infection, pneumonia and other tropical infectious diseases are risk factors for child undernutrition ${ }^{(5)}$ and potentially stronger predictors of nutritional status in this stage of early life than diet alone. Additionally, since stunting reflects a longer-term nutritional insult, our cross-sectional survey, measuring only recent dietary intake, likely did not capture dietary variation associated with this outcome. Finally, the null associations may be due to reverse causation, where mothers may have changed the dietary behaviours and physical activity of their children to be healthier in response to their perception of child's weight status or a health professional's recommendation.

Several potential limitations should be considered in the interpretation of the data. First, as we mentioned above, we cannot determine temporality and causal inference using our cross-sectional design. We are in the process of repeating this survey, two years after the initial data collection, and will be able to comment on both changes in diet over time and longitudinal diet-health associations 
in this setting. Dietary patterns and their associations with child health outcomes may change over time as the nutrition transition towards energy-dense, nutrient-poor foods and increased sedentary activity continues in Samoa. Second, our study was underpowered to assess differences in dietary patterns by gender. Our sensitivity analyses suggested there may be important differences by gender that warrant further exploration. Third, our findings may not be generalizable to the general Samoan population, as the study used a convenience sample of mother-child pairs recruited from three census regions on the Samoan island of Upolu, sampled to test specific hypotheses about the distribution of malnutrition across regions variably exposed to nutrition transition. Fourth, measurement error may have been introduced and social desirability bias may have played a role in over- or underestimation of nutrient intakes by using maternalreported FFQ to assess child dietary intake ${ }^{(49)}$. Although in our study we adapted and updated an FFQ validated among Samoan adults to attempt to reduce this error, it will be important to validate this tool for this age group specifically. We acknowledge that the quality of the diet and physical activity data derived by using questionnaires is imperfect, but there are no other validated instruments to measure these behaviours in this specific age group and setting. Fifth, although we attempted to control for household socio-economic position using annual income and the household assets inventory, both these measures are also imperfect, and there may be residual confounding. Socio-economic status and maternal education may also be associated with preferences for child body size, which we did not measure in our study, but may be influencing childhood dietary intake. Finally, PCA involves steps that involve highly subjective decisions such as the a priori grouping of food items and criteria of retaining patterns. To minimize biases in the naming and interpretation of the identified dietary patterns, nutrition staff at the Samoa Ministry of Health were asked to provide feedback on the PCA data separately from the researchers involved in data analysis. The additional PCA without grouping food items also revealed similar patterns overall. We consider PCA as the first of a series of attempts to characterize and study the influence of dietary patterns on health and development in Samoan children, and latent class analysis could be a future option as data are collected longitudinally. Similarly, our approach does not speak to diet quality, which may be better assessed using a diet index approach (although there is little consensus on an appropriate universal healthy diet score for children of this age). This again should be considered in future work in this area to complement this dietary pattern analysis.

Despite these limitations, to our knowledge, the present study is the first to identify distinct modern and neo-traditional patterns among young Samoan children, confirming the increasingly modernized dietary patterns in this age group. While following the neo-traditional diet was positively associated with child overweight/obesity in the current cross-sectional analysis, we suggest that the national nutritional guidance should continue to promote eating a variety of local, nutrient-rich foods in appropriate portion sizes to meet the energy requirements for appropriate growth and development in early life. Longitudinal research on dietary intake (quantity and quality) is needed to better understand the associations reported here. As well as continuing to follow this cohort of children and observing changes in dietary intake, our future work will focus on further exploring diet-disease relationships and determining whether the intake of specific macro- or micronutrients mediates those relationships. We also believe it is necessary to explore other methods to identify dietary patterns (cluster analysis, reduced rank regression, partial least-squares regression), because they may be particularly informative for identifying specific nutrients that mediate diet-disease relationships ${ }^{(50,51)}$, as well as constructing diet quality measures for this population group. Together, we hope that this work will lead to the further understanding of dietary patterns in early childhood, their determinants and their influences on health that is necessary to effectively communicate healthy eating messages for young children, and to inform health education and promotion campaigns targeting early childhood growth and development in Samoa.

\section{Acknowledgements}

Acknowledgements: The authors would like to thank the study participants. They are grateful to the Samoan Ministry of Health (especially Maee Ualesi Silva), staff at the Health Protection and Enforcement Division and Office of Nutrition Surveillance (Quandolita Reid-Enari and Merina Ieremia), the Samoa Bureau of Statistics and the Ministry of Women, Community and Social Development for their support and facilitation of the study. Special acknowledgement is also extended to Jennifer Park, Elizabeth Frame and the Samoan research enumerators for assisting with data collection and entry in 2015. Financial support: This work was supported by the David Dull Internship Fund, the Stolwijk Fellowship, and Yale University and University of Michigan Faculty Funds. C.C.C. was supported by the US Student Graduate Fulbright Fellowship Program. The funders had no role in the design, analysis or writing of this article. Conflict of interest: The authors declare that they have no conflicts of interest. Authorship: C.C.C. and N.L.H. conceived the study and, with D.W. and A.B., wrote the initial draft of the manuscript. C.C.C. and N.L.H. conducted the research with the support of T.N., M.S.R., C.S.-U., A.A.T. and R.L.D. D.W. was primarily responsible for the principal component analyses and, with C.C.C., C.S.-U., A.B. and N.L.H., interpreted the data. All authors read and approved the final manuscript. Ethics of human subject participation: This study was conducted according to the guidelines laid down 
in the Declaration of Helsinki and all procedures involving human subjects were approved by the Yale University Institutional Review Board and the Health Research Committee of the Samoan Ministry of Health. Written informed consent was obtained from all subjects.

\section{Supplementary material}

To view supplementary material for this article, please visit https://doi.org/10.1017/S1368980017003913

\section{References}

1. Singhal A (2016) The role of infant nutrition in the global epidemic of non-communicable disease. Proc Nutr Soc $\mathbf{7 5}$, 162-168.

2. Cameron N \& Bogin B (2012) Human Growth and Development. New York: Academic Press.

3. Adair LS, Fall CH, Osmond C et al. (2013) Associations of linear growth and relative weight gain during early life with adult health and human capital in countries of low and middle income: findings from five birth cohort studies. Lancet 382, 525-534.

4. Singhal A (2006) Early nutrition and long-term cardiovascular health. Nutr Rev 64, 5 Pt 2, S44-S49.

5. Black RE, Victora CG, Walker SP et al. (2013) Maternal and child undernutrition and overweight in low-income and middle-income countries. Lancet 382, 427-451.

6. Drewnowski A \& Popkin BM (1997) The nutrition transition: new trends in the global diet. Nutr Rev 55, 31-43.

7. Doak CM, Adair LS, Bentley M et al. (2005) The dual burden household and the nutrition transition paradox. Int $J$ Obes (Lond) 29, 129-136.

8. Popkin BM (2006) Global nutrition dynamics: the world is shifting rapidly toward a diet linked with noncommunicable diseases. Am J Clin Nutr 84, 289-298.

9. McGarvey ST (1991) Obesity in Samoans and a perspective on its etiology in Polynesians. Am J Clin Nutr 53, 6 Suppl., 1586S-1594S.

10. Keighley ED, McGarvey ST, Quested C et al. (2007) Nutrition and health in modernizing Samoans: temporal trends and adaptive perspectives. In Health Change in the Asia-Pacific Region: Biocultural and Epidemiological Approaches, pp. 147-191 [R Ohtsuka and SJ Ulijaszek, editors]. New York: Cambridge University Press.

11. Hawley NL, Minster RL, Weeks DE et al. (2014) Prevalence of adiposity and associated cardiometabolic risk factors in the Samoan genome-wide association study. Am J Hum Biol 26, 491-501.

12. Baker PT, Hanna JM \& Baker TS (1986) The Changing Samoans: Behavior and Health in Transition, vol. 5. New York: Oxford University Press.

13. NCD Risk Factor Collaboration (2016) Trends in adult body-mass index in 200 countries from 1975 to 2014: a pooled analysis of 1698 population-based measurement studies with 19.2 million participants. Lancet 387, 1377-1396.

14. Choy CC, Desai MM, Park JJ et al. (2017) Child, maternal and household-level correlates of nutritional status: a crosssectional study among young Samoan children. Public Health Nutr 20, 1235-1247.

15. Baylin A, Deka R, Tuitele J et al. (2013) INSIG2 variants, dietary patterns and metabolic risk in Samoa. Eur J Clin Nutr 67, 101-107.
16. DiBello JR, McGarvey ST, Kraft P et al. (2009) Dietary patterns are associated with metabolic syndrome in adult Samoans. J Nutr 139, 1933-1943.

17. Wang D, Hawley NL, Thompson AA et al. (2017) Dietary patterns are associated with metabolic outcomes among adult Samoans in a cross-sectional study. $J$ Nutr $\mathbf{1 7 4}$, 628-635.

18. Birch LL \& Fisher JO (1998) Development of eating behaviors among children and adolescents. Pediatrics 101, 539-549.

19. Savage JS, Fisher JO \& Birch LL (2007) Parental influence on eating behavior: conception to adolescence. J Law Med Ethics 35, 22-34.

20. Corvalan C, Kain J, Weisstaub G et al. (2009) Impact of growth patterns and early diet on obesity and cardiovascular risk factors in young children from developing countries. Proc Nutr Soc 68, 327-337.

21. Samoa Bureau of Statistics (2015) Samoa Demographic and Health Survey 2014. Apia, Samoa: Samoa Demographic and Health Survey, Government of Samoa.

22. Centers for Disease Control and Prevention (2013) National Health and Nutrition Examination Survey (NHANES) Anthropometry Procedures Manual. Atlanta, GA: CDC.

23. Swinburn BA, Ley SJ, Carmichael HE et al. (1999) Body size and composition in Polynesians. Int J Obes Related Metab Disord 23, 1178-1183.

24. World Health Organization (2011) Haemoglobin Concentrations for the Diagnosis of Anaemia and Assessment of Severity. Vitamin and Mineral Nutrition Information System. Geneva: WHO.

25. de Onis M (2006) WHO Child Growth Standards: Length/ Height-for-Age, Weight-for-Age, Weight-for-Length, Weightfor-Height and Body Mass Index-for-Age. Geneva: WHO.

26. Janz KF, Broffitt B \& Levy SM (2005) Validation evidence for the Netherlands physical activity questionnaire for young children: the Iowa bone development study. Res $Q$ Exerc Sport 76, 363-369.

27. Bielemann RM, Reichert FF, Paniz VM et al. (2011) Validation of the Netherlands physical activity questionnaire in Brazilian children. Int J Behav Nutr Phys Act 8, 45.

28. Samoa Bureau of Statistics (2011) Population and Housing Census 2011: Analytical Report. Apia, Samoa: CensusSurveys and Demography Division, SBS, Government of Samoa.

29. Newby PK \& Tucker KL (2004) Empirically derived eating patterns using factor or cluster analysis: a review. Nutr Rev 62, 177-203.

30. Willett WC, Howe GR \& Kushi LH (1997) Adjustment for total energy intake in epidemiologic studies. Am J Clin Nutr 65, 4 Suppl., 1220S-1228S.

31. Cattell RB (1966) The scree test for the number of factors. Multivariate Behav Res 1, 245-276.

32. Hu FB, Rimm E, Smith-Warner SA et al. (1999) Reproducibility and validity of dietary patterns assessed with a food-frequency questionnaire. Am J Clin Nutr 69, 243-249.

33. Dignan C, Burlingame B, Kumar S et al. (2004) The Pacific Islands Food Composition Tables. Rome: FAO.

34. Fiti-Sinclair R (2004) Knowledge, Attitudes, Belief and Practices related to the Consumption of Fruit and Vegetables in Samoa. Apia, Samoa: FAO, Sub-regional Office for the Pacific Islands.

35. Seiden A, Hawley NL, Schulz D et al. (2012) Long-term trends in food availability, food prices, and obesity in Samoa. Am J Hum Biol 24, 286-295.

36. Snowdon W, Raj A, Reeve E et al. (2013) Processed foods available in the Pacific Islands. Global Health 9, 53.

37. Smithers LG, Golley RK, Brazionis L et al. (2011) Characterizing whole diets of young children from developed countries and the association between diet and health: a systematic review. Nutr Rev 69, 449-467. 
38. Wall CR, Thompson JM, Robinson E et al. (2013) Dietary patterns of children at 3.5 and 7 years of age: a New Zealand birth cohort study. Acta Paediatr 102, 137-142.

39. Northstone K \& Emmett PM (2008) Are dietary patterns stable throughout early and mid-childhood? A birth cohort study. Br J Nutr 100, 1069-1076.

40. Durao C, Severo M, Oliveira A et al. (2017) Association of maternal characteristics and behaviours with 4-year-old children's dietary patterns. Matern Child Nutr 13, e12278.

41. Jacka FN, Ystrom E, Brantsaeter AL et al. (2013) Maternal and early postnatal nutrition and mental health of offspring by age 5 years: a prospective cohort study. J Am Acad Child Adolesc Psychiatry 52, 1038-1047.

42. Shin KO, Oh SY \& Park HS (2007) Empirically derived major dietary patterns and their associations with overweight in Korean preschool children. Br J Nutr 98, 416-421.

43. Friedman LS, Lukyanova EM, Serdiuk A et al. (2009) Social-environmental factors associated with elevated body mass index in a Ukrainian cohort of children. Int J Pediatric Obes 4, 81-90.

44. Lanigan J \& Singhal A (2009) Early nutrition and long-term health: a practical approach. Proc Nutr Soc 68 , 422-429.
45. Anzman SL, Rollins BY \& Birch LL (2010) Parental influence on children's early eating environments and obesity risk: implications for prevention. Int J Obes (Lond) 34, 1116-1124.

46. Britto PR, Lye SJ, Proulx K et al. (2017) Nurturing care: promoting early childhood development. Lancet 389, 91-102.

47. Leventakou V, Roumeliotaki T, Sarri K et al. (2016) Dietary patterns in early childhood and child cognitive and psychomotor development: the Rhea mother-child cohort study in Crete. Br J Nutr 115, 1431-1437.

48. Bailey RL, West KP Jr \& Black RE (2015) The epidemiology of global micronutrient deficiencies. Ann Nutr Metab 66, $22-33$.

49. Garrow JS (1995) Validation of methods for estimating habitual diet: proposed guidelines. Eur J Clin Nutr 49, 231-232.

50. Hoffman K, Schulze MB, Scienkiewitz A et al. (2004) Application of a new statistical method to derive dietary patterns in nutritional epidemiology. Am J Epidemiol 159, 935-944.

51. Schulze MB \& Hoffman K (2006) Methodological approaches to study dietary patterns in relation to risk of coronary heart disease and stroke. Br J Nutr 95, 860-869. 